\title{
Immunohistochemical analysis of the relationship between islet cell proliferation and the production of the enteroviral capsid protein, VP1, in the islets of patients with recent-onset type 1 diabetes
}

\author{
A. Willcox • S. J. Richardson • A. J. Bone • \\ A. K. Foulis • N. G. Morgan
}

Received: 28 January 2011 / Accepted: 19 April 2011 /Published online: 20 May 2011

(C) Springer-Verlag 2011

\begin{abstract}
Aims/hypothesis The enteroviral capsid protein, VP1, was recently shown to be present in some beta cells in more than $60 \%$ of patients with recent-onset type 1 diabetes but in very few age-matched controls. The rate of proliferation of islet cells was also markedly increased in the type 1 diabetic patients. As it has been suggested that enteroviruses replicate most efficiently in proliferating cells, we have investigated whether VP1 is preferentially present in proliferating beta cells in type 1 diabetes.

Methods Combined immunoperoxidase and immunofluorescence staining was used to record the presence of enteroviral VP1, insulin and Ki67 in the islets of recentonset type 1 diabetic patients.

Results From a total of 1,175 islets, 359 (30.5\%) contained insulin. VP1-producing endocrine cells were found in 72 islets $\left(6.1 \%\right.$ of total), all of which retained insulin. $\mathrm{Ki} 67^{+}$
\end{abstract}

A. Willcox $\cdot$ N. G. Morgan $(\bowtie)$

Institute of Biomedical and Clinical Sciences,

Peninsula Medical School, University of Exeter,

John Bull Building,

Plymouth PL6 8BU, UK

e-mail: noel.morgan@pms.ac.uk

\section{S. J. Richardson}

Peninsula Medical School, University of Plymouth,

Plymouth, UK

\section{A. J. Bone}

School of Pharmacy and Biomolecular Sciences,

University of Brighton,

Brighton, UK

\section{A. K. Foulis}

Department of Pathology, Royal Infirmary,

Glasgow, UK endocrine cells were present in 52 (4.4\%) islets, with 44 (84.6\%) of these being insulin-positive. Overall, 28 of $1,175(2.4 \%)$ islets contained both $\mathrm{Ki} 7^{+}$cells and $\mathrm{VP} 1^{+}$ cells. Dual positivity of these markers accounted for $38.9 \%$ of the total $\mathrm{VP}^{+}$islets and $53.8 \%$ of the total $\mathrm{Ki} 67^{+}$islets. No individual islet cells were dual-positive for Ki67 and VP1.

Conclusions/interpretation $\mathrm{Ki}^{+} 7^{+}$cells were frequently observed in islets that also contained $\mathrm{VP} 1^{+}$cells, suggesting that the factors facilitating viral replication may also drive islet cell proliferation. However, in an individual cell, VP1 production does not require concurrent beta cell proliferation.

Keywords Beta cell $\cdot$ Enterovirus $\cdot$ Ki67 $\cdot$ Proliferation . Type 1 diabetes $\cdot$ VP1

\section{Abbreviations \\ DAB 3,3'-Diaminobenzidine \\ PKR Protein kinase $\mathrm{R}$}

\section{Introduction}

Enteroviral infections have been increasingly implicated in the pathogenesis of type 1 diabetes [1-3]. In support of this, we have demonstrated the presence of the enteroviral capsid protein, VP1, in multiple islets of a majority of recent-onset type 1 diabetic patients [4]. VP1 correlated strongly with other markers of viral infection, including the upregulation of protein kinase R (PKR), consistent with the presence of active virus in the islet cells of patients with type 1 diabetes. Importantly, however, there was no evidence of large-scale islet cell lysis in the patients, 
suggesting that the enteroviral infection of beta cells established in type 1 diabetes is atypical and represents a persistent, non-cytopathic infection. On this basis, we have proposed that the immunopositivity for VP1 in islet cells may represent only 'the tip of the iceberg' of a larger, more covert, infection persisting at the level of viral RNA [4]. This is important because it has been reported that VP1 production and the assembly of infectious enterovirus are minimised in quiescent cells, whereas they occur extensively in actively cycling cells [5]. This raises the possibility that activation of cell proliferation may be required for re-initiation of viral protein production after the establishment of a persistent infection.

In humans, there is considerable evidence that islet cells undergo mitosis very infrequently following the immediate postnatal period $[6,7]$. However, we have shown that this changes in recent-onset type 1 diabetes such that there is a large increase in the proliferation of both alpha and beta cells [8]. Therefore, we have explored whether this increase in endocrine cell proliferation allows for the activation of enteroviral protein production in type 1 diabetes.

\section{Methods}

Donors Seven human pancreases recovered from donors with recent-onset type 1 diabetes (disease duration $\leq 18$ months) were selected from within a cohort used previously [8] and studied with ethical permission. The overall mean age was $16 \pm 5$ years (Table 1 ) and causes of death were ketoacidosis (D1, 3, 5, 7 and 9) hypoglycaemia (D8) or glioma with raised intracranial pressure (D10).

Immunohistochemistry Serial sections $(4 \mu \mathrm{m})$ were mounted on glass slides coated in (3-aminopropyl)-triethoxysilane (Sigma-Aldrich, Poole, UK) and stained using a combined immunoperoxidase and immunofluorescence technique [8]. The method was modified slightly for this study. Briefly, sections were de-waxed and rehydrated through a series of ethanol dilutions and finally distilled $\mathrm{H}_{2} \mathrm{O}$. Heat-induced epitope retrieval was performed by immersion in $1 \mathrm{mmol} / \mathrm{l}$ EDTA buffer $(\mathrm{pH} 8.0)$ in a pressure cooker and heating in a microwave oven on full power $(800 \mathrm{~W})$ for $20 \mathrm{~min}$ followed by cooling at room temperature.

Sections were incubated with a primary antibody raised against the cell proliferation marker, Ki67 (mouse, 1:200, clone MIB1) and positive staining was detected with the Dako REAL Envision Detection System (Dako, Ely, UK) using 3,3'-diaminobenzidine (DAB) as chromogen. Sections were counterstained with haematoxylin (Dako) before incubation with an antibody raised against the enteroviral capsid protein, VP1 (mouse, 1:500, clone $5 \mathrm{D} 8 / 1$ ), overnight at $4^{\circ} \mathrm{C}$. This was detected with an Alexa Fluor 568 conjugated goat anti-mouse secondary antibody. The sections were then incubated with guinea pig anti-insulin antibody (1:600) followed by Alexa Fluor 488 conjugated goat anti-guinea pig secondary antibody. DAPI $(1 \mu \mathrm{g} / \mathrm{ml})$ was included in this final step to stain cell nuclei. Controls were performed to confirm that deposition of the DAB product did not prevent the subsequent detection of insulin or VP1 by immunofluorescence. Adjacent sections were stained with rabbit anti-glucagon (1:300) using a standard immunoperoxidase technique. Antibody incubations were carried out for $1 \mathrm{~h}$ at room temperature unless otherwise specified. Primary antibodies were purchased from Dako. DAPI and Alexa Fluor conjugated secondary antibodies were purchased from Invitrogen (Paisley, UK).

Analysis Sections were analysed using a Nikon Eclipse $80 i$ microscope (Nikon, Kingston upon Thames, UK) under both brightfield and fluorescence illumination and scored for immunopositivity with relevant antisera. Statistical significance was assessed using a $\chi^{2}$ test.

Table 1 Details of the pancreas samples analysed

\begin{tabular}{llllllccc}
\hline Donor & Age & Sex & Duration of T1D & Islets $(n)$ & ICI $(n)$ & VP1 $^{+}$islets $(n)($ ICI $(n))$ & Ki67 $^{+}$islets $(n)($ ICI $(n))$ & Ki67 $^{+}$VP1 ${ }^{+}$islets $(n)$ \\
\hline D1 & 1 & F & 3 days & 183 & 48 & $10(10)$ & $12(12)$ & 7 \\
D3 & 6 & F & $<$ week & 31 & 24 & $6(6)$ & $2(2)$ & 1 \\
D5 & 11 & F & 5 days & 210 & 26 & $5(5)$ & $9(6)$ & 2 \\
D7 & 15 & M & 6 months & 294 & 33 & $3(3)$ & $5(1)$ & 0 \\
D8 & 18 & M & 4 months & 70 & 69 & $5(5)$ & $3(2)$ & 12 \\
D9 & 23 & M & 2 weeks & 113 & 103 & $16(16)$ & $9(9)$ & 7 \\
D10 & 42 & F & 18 months & 274 & 56 & $72(72)$ & $52(44)$ & 29 \\
Total & NA & NA & NA & 1,175 & 359 & & \\
\hline
\end{tabular}

ICI, insulin-containing islets; F, female; M, male; NA, not applicable; T1D, type 1 diabetes 


\section{Results}

Details of the donors used in this study are presented in Table 1. Staining of a pancreas section from each donor for glucagon revealed that 1,175 islets were present among the seven individuals (Fig. 1a). The number of islets per section ranged from 31 to 294, with a mean of $167.9 \pm 38$ islets/section. A total of 359 of the 1,175 islets were insulin-positive $(30.5 \%)$, with a range of $24-103$ per section.

Staining of the sections for VP1 and insulin revealed that 72 of 1,175 islets contained one or more $\mathrm{VP} 1^{+}$cells $(6.1 \%$; Fig. 1a and b). VP1 was present only in insulin-positive islets and the number of individual $\mathrm{VP}^{+}$cells ranged from 1 to 19 per islet.

Of the 1,175 islets studied, 52 contained $\mathrm{Ki}^{+} 7^{+}$cells $(4.4 \%)$ and 44 of these were insulin-containing islets. By virtue of their characteristic morphology, it was determined that a total of 98 individual islet cells were stained positively for $\mathrm{Ki} 67$. A total of 52 of the $98 \mathrm{Ki}^{+} 7^{+}$islet cells co-stained for insulin. The maximum number of $\mathrm{Ki}^{+} 7^{+}$ cells found within any single islet was five.

Analysis of the population of islets that contained $\mathrm{VP} 1^{+}$ and/or $\mathrm{Ki}^{+} 7^{+}$cells revealed that 28 were dual-positive for both antigens. Thus, the presence of these rarely produced proteins correlated strongly, in that $38.9 \%$ (28 of 72 ) of $\mathrm{VP}^{+}$islets also contained $\mathrm{Ki}^{+}$cells $\left(p<0.05\right.$ by $\left.\chi^{2}\right)$.
When considered from the alternative perspective, this correlation is emphasised even more strongly, as $53.8 \%$ of $\mathrm{Ki}^{+} 7^{+}$islets $(28$ of 52$)$ contained $\mathrm{VP} 1^{+}$cells $(p<0.05$ by $\chi^{2}$ ). Moreover, when account is taken of the fact that VP1 was only present in beta cells, the correlation strengthens still further with VP1 being produced in $63.6 \%$ (28 of 44 ) of $\mathrm{Ki}^{+} /$insulin-containing islets but in less than $14 \%$ of Ki67-/insulin-containing islets. These relationships are illustrated diagrammatically in Fig. 1b and an islet containing individual $\mathrm{VP}^{+}$cells and $\mathrm{Ki}^{+} 7^{+}$ cells is shown in Fig. 1c-f.

Despite the strongly positive correlation between the presence of VP1 and Ki67 among the total population of islets, no individual beta cells were dual-positive for both VP1 and Ki67 in any islet studied.

\section{Discussion}

Recent studies have established that the VP1 is present in a minority of beta cells in $60 \%$ of patients with recent-onset type 1 diabetes but is seen only very rarely in histologically normal pancreases of children dying of non-diabetic conditions [4]. This is consistent with an increasing body of evidence supporting the proposition that islet autoimmunity may be precipitated by enteroviral infection $[9,10]$. Despite this, it is clear that the infection occurring in islet

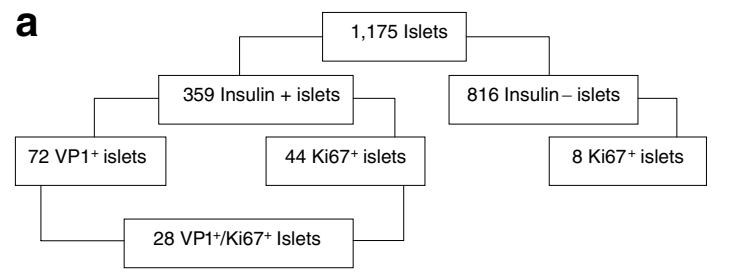

b

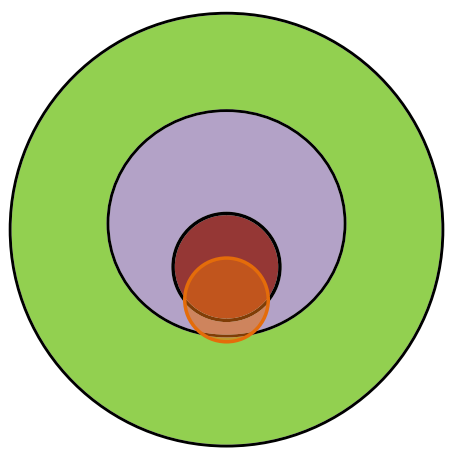

Fig. 1 The relationship between Ki67, VP1 and insulin staining in islets from donors with recent-onset type 1 diabetes. a A flow diagram showing the distribution of the islets studied $(n=1,175)$ in relation to their insulin, VP1 and Ki67 immunopositivity. b A Venn diagram illustrating the correlation between the various subgroups of islets. The total islet population is shown in green; and is subdivided into insulin-positive islets (purple circle), $\mathrm{VP}^{+}$islets (brown circle) and
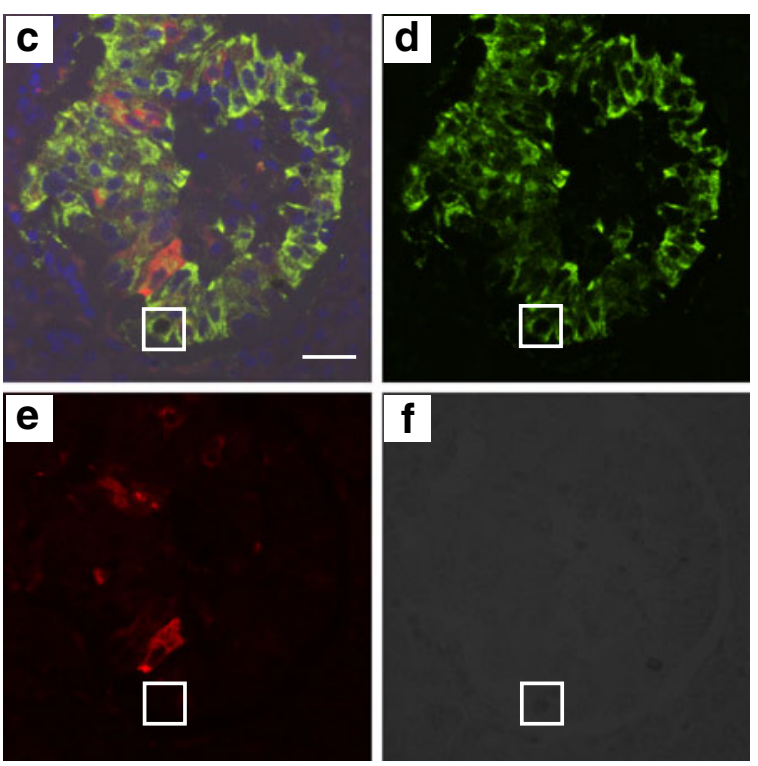

$\mathrm{Ki}^{+} 7^{+}$islets (translucent, orange circle). c An islet showing the merged images of immunostaining for Ki67 (black nuclei highlighted by the white box), VP1 (red), insulin (green) and cell nucleus (DAPI, blue). The green staining surrounding the $\mathrm{Ki} 67^{+}$nucleus indicates that this is a dividing beta cell. The individual images are shown in $\mathbf{d}$ (insulin, green), e (VP1, red) and $\mathbf{f}$ (Ki67, monochrome). Images were captured at $\times 400$ magnification (scale bar, $20 \mu \mathrm{m}$ ) 
cells in type 1 diabetes is atypical, as the large-scale cell lysis normally associated with acute enteroviral infection in some tissues is not evident in the endocrine pancreas. Rather, it appears that a low-level, persistent infection is established in which beta cell lysis is minimal (or absent) and only small numbers of beta cells produce viral protein within individual islets [4]. Given this situation, it is likely that a triggering event is required to re-activate viral protein synthesis and we hypothesised that this might be beta cell mitosis, as there is evidence that enteroviral replication is facilitated in actively cycling cells [5]. However, the present results reveal that this is not the case as, despite the fact that Ki67 and VP1 could be readily detected in the islets of recent-onset type 1 diabetic patients, not a single beta cell was found, among 1,175 islets examined, in which both proteins were co-produced. This implies very strongly that a change in the proliferative state of the beta cells is not, itself, directly permissive for enteroviral VP1 production. Indeed, it may even be the case that beta cell proliferation precludes VP1 production during persistent infection, as was recently suggested in the nervous system [11].

One caveat to this conclusion concerns the possibility that enteroviral VP1 production might be initiated during mitosis at a different point in the cycle from that when production of Ki67 occurs, such that the two do not overlap temporally. This is unlikely, as Ki67 is produced throughout the cell cycle and should persist during VP1 synthesis, if the latter also occurs during mitosis. Indeed, co-localisation of VP1 and Ki67 has been reported in other tissues [11, 12]. Therefore, we conclude that, although beta cell mitosis is observed much more frequently in recent-onset type 1 diabetes than in controls, this is not the stimulus for enteroviral VP1 production.

Despite the failure to detect co-production of Ki67 and VP1 in beta cells, we observed that Ki67 and VP1 were present within the same islets (albeit in different cells) at high frequency. One mechanism that could explain this relationship comes from earlier findings revealing that both enhanced endocrine cell proliferation and VP1 correlated with insulitis. Insulitis was present in $66 \%$ of islets containing $\mathrm{Ki}^{+} 7^{+}$endocrine cells [8] and in $38.5 \%$ of islets producing VP1 [4], in patients with recent-onset type 1 diabetes. A similar correlation has been reported between Ki67 and insulitis by Meier et al. [13] but these authors did not monitor VP1 production.

On this basis, we propose that the establishment of a persistent enteroviral infection of beta cells may represent an initiating event that leads to changes (such as chemokine secretion) that facilitate the infiltration of immune cells. The immune cells then release mitogens, including low concentrations of proinflammatory cytokines [14] that promote endocrine cell proliferation.
Acknowledgements We are grateful to the Juvenile Diabetes Research Foundation and the Diabetes Research and Wellness Foundation for funding this study.

Duality of interest The authors declare that there is no duality of interest associated with this manuscript.

\section{References}

1. Hober D, Sauter P (2010) Pathogenesis of type 1 diabetes mellitus: interplay between enterovirus and host. Nat Rev Endocrinol 6:279-289

2. Tauriainen S, Oikarinen S, Oikarinen M, Hyöty H (2011) Enteroviruses in the pathogenesis of type 1 diabetes. Semin Immunopathol 33:45-55

3. Richardson SJ, Willcox A, Bone AJ, Morgan NG, Foulis AK (2011) Immunopathology of the human pancreas in type-I diabetes. Semin Immunopathol 33:9-21

4. Richardson SJ, Willcox A, Bone AJ, Foulis AK, Morgan NG (2009) The prevalence of enteroviral capsid protein vp1 immunostaining in pancreatic islets in human type 1 diabetes. Diabetologia 52:1143-1151

5. Feuer R, Mena I, Pagarigan R, Slifka MK, Whitton JL (2002) Cell cycle status affects coxsackievirus replication, persistence, and reactivation in vitro. J Virol 76:4430-4440

6. Meier JJ, Butler AE, Saisho Y et al (2008) Beta-cell replication is the primary mechanism subserving the postnatal expansion of beta-cell mass in humans. Diabetes 57:15841594

7. Cnop M, Hughes SJ, Igoillo-Esteve M et al (2009) The long lifespan and low turnover of human islet beta cells estimated by mathematical modelling of lipofuscin accumulation. Diabetologia 53:321-330

8. Willcox A, Richardson SJ, Bone AJ, Foulis AK, Morgan NG (2010) Evidence of increased islet cell proliferation in patients with recent-onset type 1 diabetes. Diabetologia 53:2020-2028

9. Moya-Suri V, Schlosser M, Zimmermann K, Rjasanowski I, Gurtler L, Mentel R (2005) Enterovirus RNA sequences in sera of schoolchildren in the general population and their association with type 1-diabetes-associated autoantibodies. J Med Microbiol 54:879-883

10. Stene LC, Oikarinen S, Hyoty H et al (2010) Enterovirus infection and progression from islet autoimmunity to type 1 diabetes: the Diabetes and Autoimmunity Study in the Young (DAISY). Diabetes 59:3174-3180

11. Feuer R, Ruller CM, An N et al (2009) Viral persistence and chronic immunopathology in the adult central nervous system following Coxsackievirus infection during the neonatal period. $\mathrm{J}$ Virol 83:9356-9369

12. Feuer R, Whitton JL (2008) Preferential coxsackievirus replication in proliferating/activated cells: implications for virus tropism, persistence, and pathogenesis. Curr Top Microbiol Immunol 323:149-173

13. Meier JJ, Lin JC, Butler AE, Galasso R, Martinez DS, Butler PC (2006) Direct evidence of attempted beta cell regeneration in an 89 -year-old patient with recent-onset type 1 diabetes. Diabetologia 49:1838-1844

14. Maedler K, Schumann DM, Sauter N et al (2006) Low concentration of interleukin-1beta induces FLICE-inhibitory protein-mediated beta-cell proliferation in human pancreatic islets. Diabetes 55:2713-2722 